\title{
Evaluation of Response Time of a Transcutaneous Oxygen Tension Electrode
}

\author{
YOUSEF K. ABU-OSBA, BRADLEY T. THACH, ${ }^{(27)}$ AND ROBERT T. BROUILLETTE \\ The Edward Mallinckrodt Department of Pediatrics, Washington University School of Medicine, and the Division of \\ Neonatology, St. Louis Children's Hospital, St. Louis, Missouri, USA
}

\begin{abstract}
Summary
Response characteristics of a transcutaneous $\mathrm{Po}_{2}$ electrode to step changes in $\mathrm{PaO}_{2}$ were determined. In vitro lag time and $95 \%$ response time of a transcutaneous $\mathrm{Po}_{2}$ monitor were compared to in vivo response. Release of arterial occlusion was used to produce rapid local $\mathrm{PaO}_{2}$ changes in human infants and adults. In vitro lag time and $95 \%$ response time varied according to whether an increment or decrement in $\mathrm{Po}_{2}$ was produced. In vivo $95 \%$ response time of this electrode was two to six times slower than previous estimates, and it varied significantly with the magnitude of the step change, subject age, anatomic location, and local hemodynamic factors. Also, we found that in vivo lag time is two to three times faster than previously reported.
\end{abstract}

\section{Speculation}

Under steady-state conditions, transcutaneous $\mathrm{Po}_{2}$ correlates well with $\mathrm{PaO}_{2}$, but when rapid change is encountered as during oxygen administration or apnea, transcutaneous $\mathrm{PO}_{2}$ will significantly underestimate $\mathrm{PaO}_{2}$ change. On the other hand, the relatively short lag time suggests that the transcutaneous $\mathrm{PO}_{2}$ electrode may be useful in following rapid $\mathrm{PaO}_{2}$ changes qualitatively.

Monitoring transcutaneous oxygen tension (t.c. $\mathrm{Po}_{2}$ ) is a recent but already widely used technique in the care of sick infants. Under steady state conditions, t.c. $\mathrm{Po}_{2}$ has been shown to correlate well with arterial oxygen tension $\left(\mathrm{PaO}_{2}\right)(10,11,22)$. Recently, investigators have begun to use this instrument to evaluate rapid changes in $\mathrm{PaO}_{2}(1,2,17,18)$; however, the usefulness of this technique for estimating $\mathrm{PaO}_{2}$ in nonsteady state situations is unknown. We have determined the responsiveness of a t.c. $\mathrm{Po}_{2}$ electrode to arterial $\mathrm{PO}_{2}$ change and have compared the in vivo lag and response times to in vitro response. We have observed that the in vivo response of this electrode is slower than previous estimates; moreover, the response time is influenced by magnitude of step change, subject age, anatomic location, and local hemodynamic factors.

\section{METHODS AND SUBJECTS}

A commercially marketed t.c. $\mathrm{Po}_{2}$ electrode (Oxymonitor; Litton, Inc., Elk Grove, IL) was used in these studies. It was calibrated in room air and in saturated sodium bisulphite solution at a sensor temperature of $44^{\circ} \mathrm{C}$ (infants) or $45^{\circ} \mathrm{C}$ (adults) according to the manufacturer's recommendations.

\section{IN VITRO STUDIES}

We produced step changes by applying a drop of the sodium bisulphite solution on the electrode and by removing it with a clean cloth.

\section{IN VIVO STUDIES}

Vascular occlusion was used to produce step changes in dermal capillary $\mathrm{Po}_{2}(5-9)$. Arterial occlusion was achieved by inflating a blood pressure cuff 20 to $30 \mathrm{~mm} \mathrm{Hg}$ above the systolic pressure, after which there was a gradual fall in t.c. $\mathrm{Po}_{2}$. The duration of arterial occlusion was varied to change the magnitude of $\mathrm{PO}_{2}$ reduction. After sudden deflation of the cuff, t.c. $\mathrm{Po}_{2}$ increased gradually (Fig. 1). The t.c. $\mathrm{PO}_{2}$, heat flux of the electrode, and the pneumatic cuff pressure were recorded on a Beckman R611 polygraph.

\section{LAG TIME}

We defined the lag time (LT) as the time required for t.c. $\mathrm{Po}_{2}$ to begin to rise after the release of arterial occlusion (Fig. 1).

\section{RESPONSE TIME}

The difference between the lowest t.c. $\mathrm{Po}_{2}$ value produced by arterial occlusion and the steady-state t.c. $\mathrm{Po}_{2}$ of the pre- and postarterial occlusion was termed the step change in $\mathrm{Po}_{2}(\Delta$ t.c. $\mathrm{Po}_{2}$ ). The time interval after the release of arterial occlusion required for the electrode to register $95 \%$ of the step change in t.c. $\mathrm{PO}_{2}$ was termed the $95 \%$ response time (95\% RT) (Fig. 1).

\section{INFANT SUBJECTS}

We examined six infants in the St. Louis Children's Hospital Neonatal Intensive Care Unit. All the infants were medically stable; none was hypotensive, anemic or hypothermic. Informed consent from parents was obtained in each case. Average birth weight was $1438 \mathrm{~g}$ (range, 920 to $1871 \mathrm{~g}$ ); average gestational age was $31 \mathrm{wk}$ (range, 28 to $33 \mathrm{wk}$ ). We studied the infants in their warmed isolettes or on an open table under radiant heat. The t.c. $\mathrm{Po}_{2}$ electrode was placed on the middle third of the right shin. We then applied an infant-size blood pressure cuff proximal to the electrode. In these and other infants, comparison of umbilical artery $\mathrm{PaO}_{2}$ and t.c. $\mathrm{Po}_{2}$ showed a correlation comparable to other reports $(r=0.91)(10,22)$.

\section{ADULT SUBJECTS}

We performed similar arterial occlusion tests in eight healthy young adults (four females and four males). Tests were performed on the flexor surface of the arm with the electrode sensor temperature $45^{\circ} \mathrm{C}$. Arterial occlusion in the mucous membrane of the lower lip was achieved by applying pressure with a ring clamp (padded with cotton) circling the electrode. To test the effect of changes in local blood pressure, the arm was elevated from a dependent position, $28 \pm 5 \mathrm{~cm}(x \pm S . D$.) below the shoulder to a level of $28 \pm 5 \mathrm{~cm}$ above the shoulder. Twenty-four to $40 \%$ oxygen by mask was given to six adults to detect the effect of hyperoxemia.

The unpaired Student $t$ test was used for statistical analysis. 


\section{RESULTS}

IN VITRO STUDIES

For step reductions in $\mathrm{Po}_{2}$ ( $\Delta$ 157 torr), the LT was $0.2 \pm 0.06$ $(\mathrm{x} \pm$ S.D.) sec, and the $95 \% \mathrm{RT}$ was $22 \pm 4.14 \mathrm{sec}(N=16)$. For step elevations in $\mathrm{Po}_{2}(\Delta 157$ torr), LT was $0.8 \pm 0.15 \mathrm{sec}$, whereas the RT was $10 \pm 1.44 \mathrm{sec}(N=16)$. Differences between LT and $\mathrm{RT}$ for $\mathrm{PO}_{2}$ reduction and elevation are statistically significant $(P$ $<0.001)$.

\section{INFANT STUDIES}

Thirty-three arterial occlusion and release maneuvers were performed in infants. Occlusion duration was $26.8 \pm 3.9 \mathrm{sec}(\mathrm{x} \pm$ S.D.). A positive linear correlation between the $\Delta$ t.c. $\mathrm{PO}_{2}$ and $95 \%$ response time was seen (Fig. 2). The average correlation coefficient between these two variables in individual infants was $r=0.90$. The mean lag time was $3.9 \pm 1.1$ sec (Table 1 ).

\section{ADULT STUDIES}

Thirty-five arterial occlusion tests were done with the electrode on the flexor surface of the right arm of eight adults. Occlusion
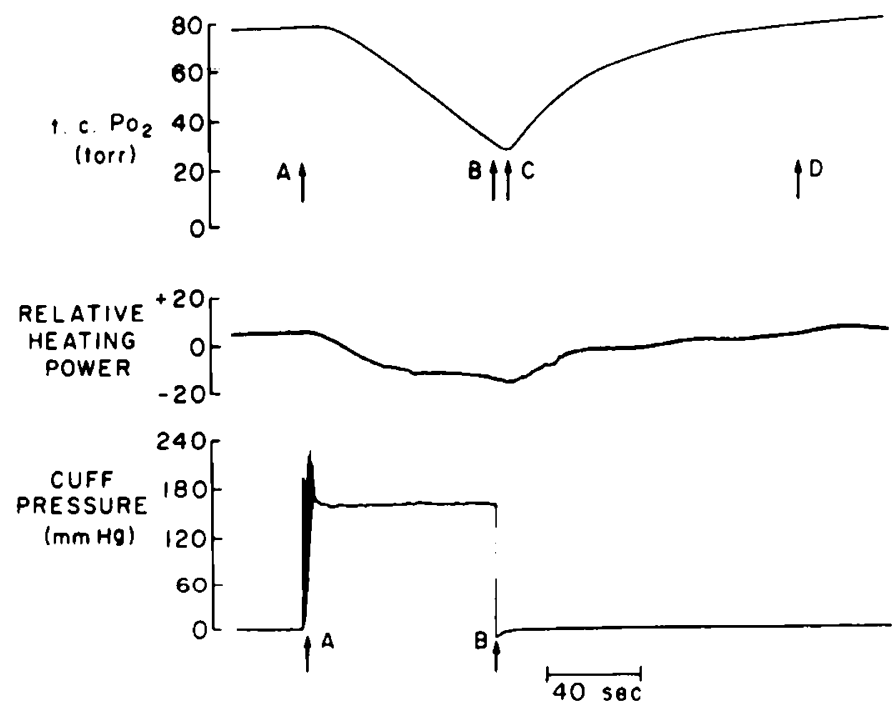

Fig. 1. In vivo determination of a transcutaneous $\mathrm{PO}_{2}$ electrode (t.c. $\left.\mathrm{PO}_{2}\right) \mathrm{LT}$ and 95\% RT after arterial occlusion release. Upper panel, t.c. $\mathrm{PO}_{2}$; middle panel, electrode relative heat flux; lower panel, pressure in the pneumatic cuff around the arm. Arrows at $A$ and $B$ show when the cuff pressure was raised and released. $C$ is the point when t.c. $\mathrm{PO}_{2}$ started to rise, and $D$ is when it reached $95 \%$ of the t.c. $\mathrm{Po}_{2}$ steady-state value. Time intervals between $B$ and $C$ and $B$ and $D$ represent LT and 95\% RT, respectively. duration was $52.3 \pm 28.4 \mathrm{sec}(\mathrm{x} \pm$ S.D.). As in infants, $\mathrm{RT}$ showed a linear correlation with the size of step change. The average correlation coefficient between these two variables in the adult subject was $r=0.96$. The adult response and lag times were greater than those in infants (Table 1); differences were statistically significant $(P<0.001$ for both).

Effect of the Electrode Site. Eight tests in the palm and eleven tests in the mucosa of the lower lip of two adults were done. RT and LT were much longer in the palm and shorter in lip mucosa than the flexor surface of the arm (Table 1). Differences between arm versus palm and arm versus lip mucosa $L T$ and $R T$ in each individual were statistically significant $(P<0.01)$.

Effect of Local Blood Pressure. In two subjects, ten tests were done in the flexor surface of the arm when the whole limb was in dependent position (mean local blood pressure, $120 / 80 \mathrm{~mm} \mathrm{Hg}$ ) and after elevation above the shoulder (mean local blood pressure, $80 / 50 \mathrm{~mm} \mathrm{Hg}$ ). LT and RT increased after elevation of the arm. In each subject, differences from the dependent position were statistically significant $(P<0.05)$. The steady state t.c. $\mathrm{Po}_{2}$ tended to decrease after each elevation of the arm and increased to the previous level when the arm was back in the dependent position.

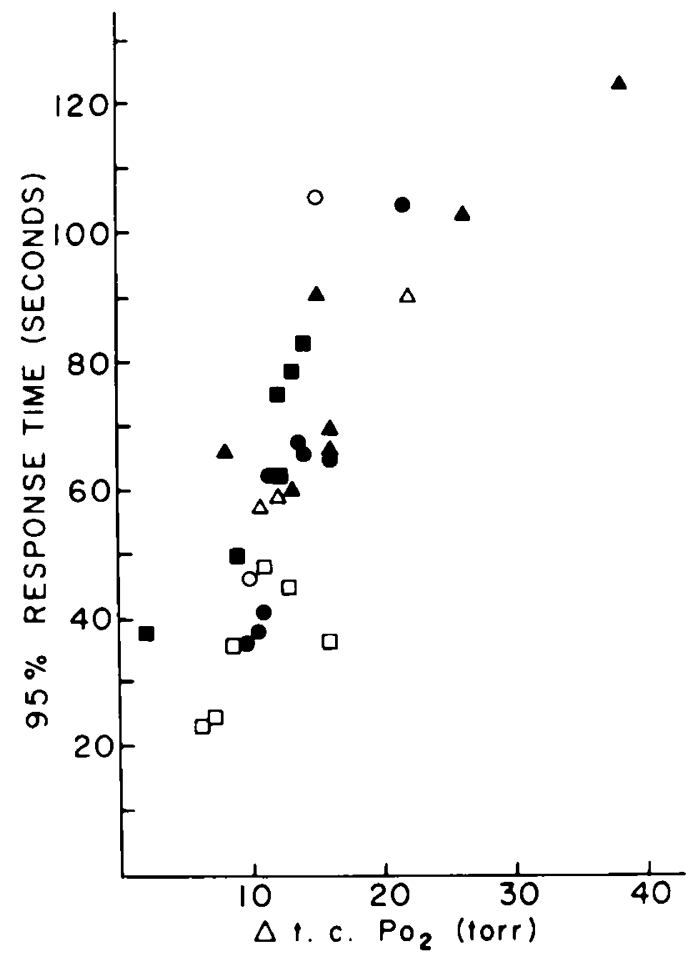

Fig. 2. Correlation between step change in transcutaneous oxygen tension $\left(\Delta\right.$ t.c. $\left.\mathrm{Po}_{2}\right)$ and $95 \%$ response time in six infants. Different symbols represent values for different subjects.

Table 1. t.c. $\mathrm{Po}_{2}$ electrode lag and $95 \%$ RTs for step charges in $\mathrm{PO}_{2}\left(\Delta\right.$ t.c. $\left.\mathrm{PO}_{2}\right)$ in vivo and in vitro studies

\begin{tabular}{lcccc}
\hline \multicolumn{1}{c}{ Site and maneuver } & No. of subjects & Change in t.c. $\mathrm{PO}_{2} /$ torr & LT/sec & 95\% RT/sec \\
\hline In vivo studies' & & & & \\
Infant leg & 6 & $16.4 \pm 2.9^{2}$ & $3.9 \pm 1.1$ & $76.5 \pm 20.3$ \\
Adults flexor surface of the arm & 8 & $18.8 \pm 2.8$ & $9.2 \pm 2.5$ & $121.5 \pm 38.4$ \\
Adults palm & 2 & $19.0 \pm 4.2$ & $44.4 \pm 14.4$ & $1032.5 \pm 24.8$ \\
Adults mucosa of the lip & 2 & $19.5 \pm 4.0$ & $4.8 \pm 1.1$ & $51.0 \pm 1.4$ \\
Adults arm dependent & 2 & $19.6 \pm 3.1$ & $6.7 \pm 0.9$ & $96.2 \pm 16.9$ \\
Adults arm elevated & 2 & $24.0 \pm 0.0$ & $11.6 \pm 2.0$ & $174.0 \pm 24.9$ \\
Adults arm breathing 40\% oxygen & 6 & $22.3 \pm 4.9$ & $10.6 \pm 2.2$ & $126.8 \pm 30.7$ \\
& & $157 \pm 0$ & $0.2 \pm 0.06$ & $22.00 \pm 4.14$ \\
In vitro studies & Descending change & $157 \pm 0$ & $0.8 \pm 0.15$ & $10.00 \pm 1.44$ \\
\hline
\end{tabular}

\footnotetext{
' In vivo $\mathrm{LT}$ and $\mathrm{RT}$ for 15 to 25 torr step changes in t.c. $\mathrm{PO}_{2}$ postarterial occlusion release.

${ }^{2}$ Mean \pm S.D.
} 
Table 2. Published values for in vitro and in vivo response of t.c. $\mathrm{PO}_{2}$ electrode

\begin{tabular}{|c|c|c|c|c|c|c|}
\hline References & Electrode type & $\begin{array}{c}\text { Electrode place- } \\
\text { ment }\end{array}$ & Subjects & RT (sec) & LT (sec) & Method \\
\hline Huch et al. $(10,11)$ & Huch & In vitro & & $8-12(95 \%)$ & & Not described \\
\hline Rooth $(20,21)$ & Huch & In vitro & & $8-10(-)$ & & Not described \\
\hline Dennhardt et al. (3) & Huch & In vitro & & $6-9 \quad(-)$ & & Not described \\
\hline Versmold et al. (24) & Huch, Litton & In vitro & & $16.8 \quad(95 \%)$ & & $\begin{array}{l}\text { Step change } \mathrm{FIO}_{2} \text { (140 to } \\
0 \text { torr) }\end{array}$ \\
\hline Peabody et al. (18) & Huch & In vivo & Infants & $(95 \%)$ & & Not described \\
\hline Dennhardt et al. (3) & Huch & In vivo & Unspecified & $20-30(-)$ & & Step change $\mathrm{FIO}_{2}$ \\
\hline Litton (16) & Huch & In vivo & Unspecified & $(95 \%)$ & & Not described \\
\hline Rooth $(20,21)$ & Huch & In vivo & Infants & & 10 & Not described \\
\hline Lesouöf et al. (15) & Huch & In vivo & Infants & & 10 & Step change $\mathrm{FIO}_{2}$ \\
\hline Huch and Huch (10) & Huch & In vivo & Unspecified & & 10 & Step change $\mathrm{FIO}_{2}$ \\
\hline Swanstrom et al. (23) & Huch & In vivo & Infants? & & $20-30$ & Step change $\mathrm{FIO}_{2}$ \\
\hline Rooth (20) & Huch & In vivo & Adult & & $20-30$ & Not described \\
\hline Jacobsen and Löfgren (12) & Radiometer & In vivo & Infants & $20-25(-)$ & & Step change $\mathrm{FIO}_{2}$ \\
\hline Krauss et al. (13) & Eberhard & In vivo & Infants & $60-90(-)$ & & Step change $\mathrm{FIO}_{2}$ \\
\hline \multirow[t]{2}{*}{ Versmold et al. (24) } & Huch, Litton & In vivo & Infants & $82.5 \quad(50 \%)$ & & Step increase in $\mathrm{FIO}_{2}$ \\
\hline & & & Infants & $51.1 \quad(50 \%)$ & 16.7 & Step decrease in $\mathrm{FIO}_{2}$ \\
\hline
\end{tabular}

Effect of Breathing Oxygen. When 24 to $40 \%$ oxygen by mask was given to six adults, the lowest t.c. $\mathrm{Po}_{2}$ postarterial occlusion was more than 70 torr. The RT showed the same relationship with size of $\Delta$ t.c. $\mathrm{Po}_{2}$. Results are shown in Table 1.

\section{DISCUSSION}

\section{IN VITRO RESPONSE}

Our in vitro 95\% response time for increases in $\mathrm{Po}_{2}$ is comparable to previously reported values although the methodology used in previous reports is not described (Table 2). We found in vitro response of the t.c. $\mathrm{PO}_{2}$ electrode to depend on the direction of the $\mathrm{PO}_{2}$ step change. This difference probably reflects differences in the techniques used to produce the step changes because response in liquid which we used to produce a step reduction in $\mathrm{Po}_{2}$ might be expected to be slower than response in gas, which we used to produce a step increment in $\mathrm{Po}_{2}$. The values obtained during reduction of $\mathrm{PO}_{2}$, i.e., the longer of the two in vitro response times, are probably more applicable to the expected performance of the electrode when measuring t.c. $\mathrm{Po}_{2}$ because a liquid film is interposed between the skin surface and the electrode membrane.

\section{IN VIVO RESPONSE}

We used arterial occlusions to reduce skin $\mathrm{Po}_{2}$ and occlusion release to produce a sudden increment in local $\mathrm{PaO}_{2}$ ("step change"). The rationale for using this technique is provided by the studies of Evans and Naylor (5-9). They found that t.c. $\mathrm{Po}_{2}$ is determined by oxygen tension in the venous arm of the superficial dermal capillary loops. They concluded that increasing skin blood flow by warming the skin or stopping blood flow altogether greatly reduces the $\mathrm{A}-\mathrm{V} \mathrm{Po}_{2}$ difference between arterial and venous ends of the capillary loop. During vascular occlusion, intradermal $\mathrm{O}_{2}$ tension falls as a result of local tissue metabolism. In the present studies, the electrode was positioned within $2 \mathrm{~cm}$ of the blood pressure cuff; therefore, we estimate that arterial blood from above the cuff reached the skin capillaries in a fraction of the subject's circulation time. This assumption is supported by our observations that LT was as short as $2 \mathrm{sec}$. Only part of that interval would be due to blood flow transit time because the intrinsic LT of the electrode was $0.2 \mathrm{sec}$ and also because oxygen diffusion time across the avascular epidermal layer would account for part of the LT. Hence, we believe that arterial occlusion release approximates a true step change in $\mathrm{PaO}_{2}$. Other investigators have assessed in vivo response of the electrode by changing inspired oxygen concentration (Table 2). However, changes in inspired oxygen require time both for alveolar mixing and transit from lung to arm, and consequently, the change in $\mathrm{PaO}_{2}$ is relatively slow using this method. Aside from the obvious disadvantage of the present technique which does not allow step decreases in arterial $\mathrm{PO}_{2}$, we believe that it is superior to the previously described method.

In the present study, the in vivo LT was less in infants than in adults. This likely results from the infant's thinner epidermal layer allowing a shorter path for oxygen diffusion. This age-related difference is also consistent with our observation of short LT in nonkeratenized skin (lip) and long LT in areas with extremely thick epidermis (palm). Our values are one-sixth to one-half those reported by others (Table 2 ). This disagreement is likely accounted for by the alveolar gas mixing time and lung to arm transit time inherent in previously used methods.

We have shown that $\mathrm{RT}$ to a rise in $\mathrm{Po}_{2}$ is a function of the magnitude of the $\mathrm{PaO}_{2}$ step change. This conclusion seems valid even though the precise size of the step change was unknown because fall in dermal $\mathrm{Po}_{2}$ after occlusion was detected by the fall in t.c. $\mathrm{Po}_{2}$. Taking the electrode $\mathrm{RT}$ into account, we have underestimated the actual capillary $\mathrm{Po}_{2}$ postarterial occlusion in each case. For equivalent step changes in t.c. $\mathrm{Po}_{2}$, response time in infants was shorter than in adults. In adults, response was fastest in nonkeratinized areas (lip) and slowest in areas with thickest epidermis (palm). These observations appear to be consistant with those of Purvis (19) who found that thick membranes used in making $\mathrm{Po}_{2}$ electrodes lengthened response time.

Our values for in vivo RT are two to six times longer than previously reported values (Table 2 ). Precise comparison is difficult because detailed description of methods has been lacking in these reports. In some cases, it appears that LT and RT have been used interchangeably. Also, the relation of RT to magnitude of step change was not evaluated in previous studies. It seems unlikely that our long RT is due to change in skin circulation produced by hypoxia because similar RTs were noted in individuals breathing $40 \%$ oxygen and room air. A potential problem with the present techniques is postocclusion hyperemia. However. for periods of ischemia of less than $5 \mathrm{~min}$, the change in skin circulation is quite small (4). Furthermore, with an electrode temperature of $44^{\circ} \mathrm{C}$ in infants and $45^{\circ} \mathrm{C}$ in adults, a maximal vessel dilation is expected. However, our results showing that limb elevation affects $\mathrm{RT}$ suggest that local vascular influences can be important.

Krauss et al. (13) monitored t.c. $\mathrm{Po}_{2}$ simultaneously with ear oxymetry. Their published polygraphic records suggest that t.c. $\mathrm{PO}_{2}$ response to changes in arterial $\mathrm{Po}_{2}$ is slow compared to change in arterial saturation suggesting that damping of the t.c. $\mathrm{Po}_{2}$ signal will occur during rapid $\mathrm{PaO}_{2}$ change. The amount of damping would depend on the rate of $\mathrm{PaO}_{2}$ change. In studies of newborn animals, $\mathrm{PaO}_{2}$ has been observed to fall at a rate of 2 to 3 torr $/ \mathrm{sec}$ after airway obstruction (14). In other animal studies, using an 
intravascular electrode with extremely rapid response (95\% response, $0.3 \mathrm{sec}$ ), Purves (19) noted similar rates of change in $\mathrm{PaO}_{2}$ after step change in inspired oxygen tension or spontaneous deep breaths. Considering the present RT determinations, we conclude that significant divergence of $\mathrm{PaO}_{2}$ from t.c. $\mathrm{Po}_{2}$ can be expected in human subjects in a variety of circumstances where rapid changes in $\mathrm{PaO}_{2}$ are encountered. That is t.c. $\mathrm{Po}_{2}$ will be a highly damped measure of $\mathrm{PaO}_{2}$, and when used to follow rapid transient $\mathrm{PaO}_{2}$ changes, such as occur during apneic spells, it would significantly underestimate the true $\mathrm{PaO}_{2}$ change. This suggests limited use for $\mathrm{t}$.c. $\mathrm{Po}_{2}$ as an apnea alarming device. These are limitations which have previously received little comment $(17,22)$. On the other hand, our observations do not detract from the established value of the t.c. $\mathrm{Po}_{2}$ electrode in relatively steady state situations. Also, our observations of a short LT for reflecting $\mathrm{PaO}_{2}$ change suggest that the t.c. $\mathrm{Po}_{2}$ electrode may be useful as a noninvasive technique for following rapid $\mathrm{PaO}_{2}$ changes qualitatively.

\section{REFERENCES AND NOTES}

1. Abu-Osba, Y. K., Thach, B. T., Wilson, S. L., Brouillette, R. T., and Mathew, O. P.: Apnea and increased transcutaneous (t.c. $\mathrm{PO}_{2}$ ) following sighs (augmented breaths) in preterm infants. Pediatr. Res., 14: 588 (1980).

2. Brouillette, R. T., Thach, B. T., Abu-Osba, Y. K., and Wilson, S. L.: Hiccups in infants: characteristics and effects on ventilation. J. Pediatr., $96: 219$ (1980).

3. Dennhardt, R., Fricke, M., Mahal, S., Huch, A., and Huch, R.: Transcutaneou $\mathrm{PO}_{2}$ monitoring in anaesthesia. Eur. J. Intensive Care Med., 2: 29 (1976).

4. Dornhorst, A. C.: Hyperaemia induced by exercise and ischaemia. Br. Med. Bull., 19: 137 (1963).

5. Evans, N. T. S., and Naylor, P. F. D.: Steady states of oxygen tension in human dermis. Respir. Physiol., 2: 46 (1966/1967).

6. Evans, N. T. S., and Naylor, P. F. D.: The dynamics of changes in dermal oxygen tension. Respir. Physiol., 2: 61 (1966/1967).

7. Evans, N. T. S., and Naylor, P. F. D.: The oxygen tension gradient across human epidermis. Respir. Physiol., 3: 38 (1967).

8. Evans, N. T. S., and Naylor, P. F. D.: The systemic oxygen supply to the surface of human skin. Respir. Physiol.. 3: 21 (1967).

9. Evans, N. T. S., and Naylor, P. F. D.: The use of multicathode surface oxygen electrodes for studying the microcirculation of human skin. Prog. Respir. Res., 3: 161 (1969).

10. Huch, A., and Huch, R.: Transcutaneous noninvasive monitoring of $\mathrm{Po}_{2}$. Hosp. Pract., 6: 43 (1976).

11. Huch, R., Lubbers, D. W., and Huch, A.: Reliability of transcutaneous monitoring

Copyright ( $) 1981$ International Pediatric Research Foundation, Inc. $0031-3998 / 81 / 1502-0143502.00 / 0$ of arterial $\mathrm{PO}_{2}$ in newborn infants. Arch. Dis. Child., 49: 213 (1974).

12. Jacobson, $\mathrm{L}$., and Löfgren, $\mathrm{O}$.: Transcutaneous monitoring of $\mathrm{PO}_{2}$ in differen skin areas in the neonate and in the scalp of the fetus during labor. Methodological and physiological observations. Acta. Obst. Gynecol. Scand. (Suppl.) 66: 55 (1977).

13. Krauss, A. N., Waldman, S., Frayer, W. W., and Auld. P. A. M.: Noninvasive estimation of arterial oxygenation in newborn infants. J. Pediatr., 93: 275 (1979).

14. Lawson, E. E., and Thach, B. T.: Respiratory patterns during progressive asphyxia in newborn rabbits. J. Appl. Physiol. Respir. Environ. Exercise Physiol., 43. 468 (1977).

15. LeSouëf, P. N., Morgan, A., Soutter, L., Reynolds, E., and Parker, D.: Comparison of transcutaneous oxygen tension with arterial oxygen tension in newborn infants with severe respiratory illness. Pediatrics, 62: 692 (1978)

16. Litton Medical Electronics: Product Information, Litton Oxymonitor. (Elk Grove. IL, 1977.)

17. Martin, U. J., Okkin, A., and Katona, P. G.: Effect of lung volume on expiratory time in the newborn infant. J. Appl. Physiol. Respir. Environ. Exercise Physiol. 45: 18 (1978).

18. Peabody, J. L., Gregory, G. A., Willis, M. M., and Tooley, W. H.: Transcutaneous oxygen tension in sick infants. Am. Rev. Respir. Dis., 118: 83 (1978).

19. Purves, M. J.: Fluctuations of arterial oxygen tension which have the same period of respiration. Respir. Physiol., I: 281 (1966).

20. Rooth, G.: Transcutaneous technique for continuous oxygen tension measurements. Rev. Perinat. Med., I: 179 (1976).

21. Rooth, G.: Transcutaneous oxygen tension measurements in newborn infants Pediatrics, 55: 232 (1975)

22. Strauss, J., Bancalari. E., Feller, R., Gannon, J., Beran, A. V., and Baker, R. Clinical aspects of continuous neonatal oxygen monitoring. Fed. Proc., 38 . 2478 (1979)

23. Swanström, S., Villa Elisaga, I., Cardona, L., Cardenes, A., Mendez-Bauer, C., and Rooth. G.: Transcutaneous $\mathbf{P O}_{2}$ measurements in seriously ill newborn infants. Arch. Dis. Child., 50: 913 (1975).

24. Versmold, H. T., Linderkamp, O., Stuffer, K. H., Holzmann, M., and Riegel, K. $\mathrm{P}$. Vivo vs. in vitro response time of transcutaneous $\mathrm{PO}_{2}$ electrodes. Acta Anaesthesiol. Scand. Suppl., 68 : 40 (1978).

25. Robert Brouillette was a recipient of an American Lung Association Training Fellowship.

26. The authors are indebted to Drs. D. Dietzler, R. Marshall, and C. Smith for their help and suggestions and to the St. Louis Children's Hospital Neonatal Intensive Care Unit nursing staff for assistance.

27. Requests for reprints should be addressed to: Dr. B. T. Thach, Division of Neonatology, St. Louis Children's Hospital, 500 S. Kingshighway Blvd., P.O Box 14871, St. Louis, MO 63178 (USA).

28. This research was supported in part by a grant from The Life Seekers and by NIH grant HD-10993-03.

29. Received for publication February 8,1980

30. Accepted for publication August 4, 1980. 